\title{
Chemical composition of subcritical water extraction extract of Tribulus Terrestris
}

\author{
Ersin Akgollu ${ }^{\mathrm{a}}$, Ahmet Umay ${ }^{\mathrm{b}}$, Murat Turk ${ }^{\mathrm{a}}$, Ramazan Bilgin ${ }^{\mathrm{a}}$ \\ ${ }^{a}$ Department of Chemistry(Biochemistry Division), Arts \& Science Faculty, Cukurova University, \\ 01330 Adana, Turkey \\ ${ }^{\mathrm{b}}$ Osmaniye Vocational School Environmental Protection Technology Section, Osmaniye Korkut Ata \\ University, 80010 Osmaniye, Turkey
}

\section{rbilgin@cu.edu.tr}

Keywords: Tribulus Terrestris, subcritical water extraction.

Subcritical water extraction of Tribulus terrestris leaves and fruits was performed at $100{ }^{\circ} \mathrm{C}$ and 60 atm for $30 \mathrm{~min}$. Chemical composition of volatile extracts was investigated. A simple lactone compound Loliolide $(23,82 \%)$ was main components associated with 26 identified molecules which are mostly oxygenated compounds.

\section{Introduction}

In human health, plants have an important role due to certain chemicals produced by them as waste material during their metabolism.

Tribulus terrestris is one of commonly used in folk medicine in Turkey. It's mostly used due to biological activities such as diuretic, against colicky pains, hypertension and hypercholesterolemia. It is also known to increase the free serum testosterone, and then effective in the treatment of sexual and erectile dysfunction. It has also a protective effect on genetic damage and stimulates melanocyte proliferation in the treatment of vitiligo. Several researchers were reported that Tribulus terrestris contains alkaloids, steroids, flavonoids and carbohydrates [1-11].
Subcritical water extraction (SCWE) is a pro-environmental process as an alternative to conventional extraction methods like solvent extraction. Under SCWE conditions, the dielectric properties of water change. The dielectric constant of water is a measure of the separation of ions from each other in other words its polarity. Under subcritical conditions, the reduced dielectric constant of water increases its dissolution properties, and therefore, it results in non-polar substances being more water soluble. This simple method which provides high efficiency, saving time and energy, has been widely used extraction and fractionation of compounds to be obtained with a greatest specificity. Subcritical water extraction is increasingly used to extract valueadded products from plant materials [12]. 
The aim of this study was to explore quantity of loliolide a most common mono terpenoid hydroxyl lactone extracted from Tribulus terrestris by using SCWE process which providing appropriate subcritical conditions.

\section{Experimental part}

\section{Material and Methods}

\section{Plants material}

Dried Tribulus terrestris was purchased from local dealer in Adana, Turkey, and was used as received.

\section{Sub-critical water extraction (SbCWE)}

Sub-critical water extraction was carried out in a laboratory built apparatuses. To remove dissolved oxygen the water was sonicated then was used in an HPLC pump. Experiments were performed at a constant flow rate, $1 \mathrm{~mL} \cdot \mathrm{min}^{-1}$. The extractor heated in a temperature programmable oven. To equilibrate the water, a 2 $\mathrm{m}$ long pre-heated coil was used at desired temperature. The capacity of the extraction cell was $14 \mathrm{ml}$ and equipped with $10 \mu \mathrm{m}$ frit at the inlet and outlet. The extraction cell was connected to a $1 \mathrm{~m}$ cooling loop outside of the oven. $2 \mathrm{~g}$ of Tribulus terrestris leaves and fruits were used. Extraction was carried out at $100{ }^{\circ} \mathrm{C}$ temperature, and $60 \mathrm{~atm}$ pressure for $30 \mathrm{~min}$.

After a certain time, extract was collected in dichloromethane (DCM), and followed by a liquid-liquid extraction step to separate the essential oil of Tribulus terrestris.

\section{$G C-M S$ analysis}

Qualification and quantification of essential oil of SbCWE extract was carried out by using a Finnigan-Trace GC-MS equipped with an auto sampler. $1 \mu \mathrm{L}$ of sample was injected using split method with 50 split ratio. Chromatographic separations were performed with a Zebron ZB-5 capillary column (5\% phenyl-95\% dimethylpolysiloxane, $0.25 \mathrm{~mm}$ i.d. $\times 60 \mathrm{~m}$, film thickness $0.25 \mu \mathrm{m}$ ). Helium was used a carrier gas with, flow rate 1.0 $\mathrm{mL} \cdot \mathrm{min}^{-1}$ The column temperature was programmed from 70 to $240{ }^{\circ} \mathrm{C}$ at $3^{\circ} \mathrm{C} \cdot \mathrm{min}^{-1}$ and the temperature of the injection port was $250{ }^{\circ} \mathrm{C}$. The ionization voltage applied was 70 $\mathrm{eV}$, mass range $m / z \quad 41-400$ a.m.u. The separated components were identified tentatively by matching with GC-MS results of National Institute of Standards and Technology (NIST) mass spectral library data because their reference reagent were not available. The quantitative determination was carried out based on peak area integration.

\section{Results and discussion}

To determine the chemical composition of volatile fraction of Tribulus terrestris extract, GC-MS analysis was employed (Table 1).

Loliolide which is a most common mono terpenoid hydroxyl lactone was the most abundant volatile compound in SbCWE extract of Tribulus terrestris (23.8 \%). Despite a simple structure (Figure 1), Loliolide has a wide 
spectrum of biological activity such as astringent, antipyretic, anti-inflamatory and vasodilatory effects [11]. Apart from Loliolide, a derivative 2-4(H)-Benzofuranone, 5,6,7,7atetrahydro-4,4,7a-tri methyl was the second most abundant component of extract of Tribulus terrestris. The other main components of volatile compound of the extract are coniferol (7.9\%), 6aza thymine (7.8\%) vanilline (4.4\%), Ethylmethylmaleimide (3.8 \%), p-eugenol (3.0 $\%)$, carvone (3.1\%), carvacrol (2.4\%), p-vinyl guaiacol (1.7\%), Syringaldehyde( $1.7 \%$ ) and methyl eugenol (1.6\%). The relative amount of other detected and identified compounds was lower than $1 \%$. It's clearly seen that almost all the flavour compounds which were extracted from Tribulus terrestris via SbCWE, are oxygenated mono terpenes, oxygenated aromatic propenes or phenolic mono terpenes. These results important because subcritical water helps to isolate preferently valuable oxyganeted mono terpens from Tribulus terrestris [13-16].

During the SbCWE, it's possible to see degradation products such as short chain alcohols, aldehydes, aromatic and aliphatic compounds. However, we didn't observe any of these molecules in the GC-MS spectra. Hence, it can be suggest that shown that subcritical water extraction of Tribulus terrestris at $100{ }^{\circ} \mathrm{C}$ and $60 \mathrm{~atm}$ is a suitable extraction method for the isolation of valuable components.

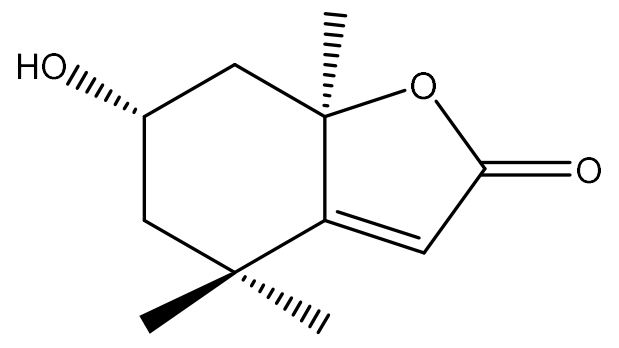

Loliolide

Figure 1. Structure of Loliolide

\section{Conclusions}

The results showed that $\mathrm{SbCWE}$ is a suitable extraction method to recover the important components of Tribulus terrestris. Loliolide and its derivatives such as 2-4(H)-Benzo furanone, 5,6, 7,7a-tetrahydro-4,4,7a-tri methyl are mostly presented in small quantities in plants and animals. Therefore extraction and purification of Loliolide is important and labor-intensive. Since, SbCWE gave a good isolation for Loliolide and 2-4(H)-Benzofuranone, 5,6,7,7atetrahydro-4,4,7a-tri methyl, to enhance the amount of extracted Loliolide from Tribulus terrestris new parameters should be tried.

\section{Acknowledgements}

This work supported by Research Grant from Çukurova University. 
FRENCH-UKRAINIAN JOURNAL OF CHEMISTRY (2018, VOLUME 06, ISSUE 02)

Table 1. Essential oil components of Tribulus terrestris leaves and fruits were obtained by SbCWE method and they were analyzed by GC-MS

\begin{tabular}{|c|c|c|c|}
\hline \multirow[t]{2}{*}{$\mathrm{RT}(\min )$} & \multirow[t]{2}{*}{ Compounds } & \multicolumn{2}{|c|}{ Relative amount \% } \\
\hline & & SbcWE & Brewing \\
\hline 11,74 & Camphor & 2,90 & \\
\hline 15,32 & Ethylmethylmaleimide & 3,84 & \\
\hline 15,59 & inosine & - & 21,61 \\
\hline 15,80 & Carvone & 3,11 & \\
\hline 16,96 & Nonanoic acid & 0,19 & \\
\hline 18,70 & p-Vinylguaiacol & 1,68 & \\
\hline 20,56 & p-Eugenol & 2,99 & \\
\hline 22,19 & vanilline & 4,41 & \\
\hline 22,56 & Methyleugenol & 1,55 & \\
\hline 22,94 & n-formylmorpholine & - & 78,38 \\
\hline 25,50 & Veratral & 0,38 & \\
\hline 25,72 & Acetovanillone & 0,85 & \\
\hline 27,42 & $\begin{array}{c}\text { 2(4H)-Benzofuranone, 5,6,7, 7a-tetrahydro- } \\
4,4,7 \text { a trimethyl }\end{array}$ & 12,94 & \\
\hline 29,24 & 6-azathymine & 7,81 & \\
\hline 31,39 & Elemicine & 0,53 & \\
\hline 31,56 & 4-fluoro-1,2-xylene & 1,98 & \\
\hline 31,67 & Acetophenone & 0,31 & \\
\hline 31,84 & 3-Oxo- $\alpha$-ionol & 1,08 & \\
\hline 31,96 & verbanone & 0,98 & \\
\hline 32,40 & Syringaldehyde & 1,64 & \\
\hline 32,54 & carvacrol & 2,58 & \\
\hline 32,77 & 4-Oxo- $\alpha$-ionone & 0,73 & \\
\hline 33,43 & $\beta$-Ionone epoxide & 2,93 & \\
\hline 33,58 & Hidroxy- $\beta$-ionone & 3,25 & \\
\hline 35,41 & Coniferol & 7,88 & \\
\hline 36,89 & Loliolide & 23,82 & \\
\hline 38,01 & Phenol, 4-methoxy-, acetate & 3,22 & \\
\hline 38,65 & Indole-3-aldehyde & 1,60 & \\
\hline 47,66 & Scopoletin & 0,51 & \\
\hline
\end{tabular}




\section{References}

[1] Sardar A. Farooq, Talat T. Farook and Salim H. Al-Rawahy. Natural Products and Their Active Compounds Editors: M. Essa, A. Manickavasagan, and E. Sukumar, Nova Science Publishers, Inc ISBN: 978-162100, 2012, pp. 153-159.

[2] Wu G, Jiang S, Jiang F, Zhu D, Wu H, Jiang S.. Steroidal glycosides from Tribulus terrestris. Phytochemistry. 1996;42:1677-81.

[3] Wu TS, Shi LS, Kuo SC. Alkaloids and other constituents from Tribulus terrestris. Phytochemistry. 50: 1411-15. Joshi, V.S. B.B. Parekha, M.J. Joshia, A.B. Vaidyab. 2005. Herbal extracts of Tribulus terrestris and Bergenia ligulata inhibit growth of calcium oxalate monohydrate crystals in vitro. Journal of Crystal Growth. 1999; 275:1403-1408.

[4] Saleh NAM, Ahmed AA., Abdalla MF. Flavonoid glycosides of Tribulus pentandrus and $\mathrm{T}$. Terrestris. Phytochemistry. 1982;21:1995-2000.

[5] Su L, Chen G, Feng SG, Wang W, Li ZF, Chen H, Liu YX, Pei YH.. Steroidal saponins from Tribulus terrestris. Steroids. 2009;74:399-403.

[6] Teo CC, Tan SN, Yong JWH, Hew CS, Ong, ES. Pressurized hotwater extraction (PHWE). J. Chromatogr. A 2010;1217:2484-2494.

[7] Reddy HK, Muppaneni T, Sun Y, Li Y, Ponnusamy S, Patil PD, Dailey P, Schaub T, Holguin FO, Dungan B. Subcritical water extraction of lipids from wet algae for biodiesel production. Fuel. 2014;133:7381.

[8] Yang L, Qu H, Mao G, Zhao T, Li F, Zhu B, Zhang B, Wu X. Optimization of subcritical water extraction of polysaccharides from Grifola frondosa using response surface methodology. Pharmacogn. Mag. 2013;9:120-129.
[9] Ndlela SC, Moura JMLND, Olson NK, Johnson LA. Aqueous extraction of oil and protein from soybeans with subcritical water. J. Am. Oil Chem. Soc. 2012;89:1145-1153.

[10] Sereewatthanawut I, Prapintip S, Watchiraruji K, Goto M, Sasaki M, Shotipruk A. Extraction of protein and amino acids from deoiled rice bran by subcritical water hydrolysis. Bioresour. Technol. 2008;99:555-561.

[11] Fujita E, Saeki Y, Ochiart M. Investigation of the neutral constituents of Lythrum Salicoria L. Bulletin of the Institute for chemical research 1972;50:327-331.

[12] Munir MT, Kkeirkhah H, Baroutian S, Quek SY, Young BR. Subcritical water extraction of bioactive compounds from waste onion skin. Journal of Cleaner Production, 2018;183:487-494.

[13] Vladic J, Canli O, Pavlic B, Zekovic Z, Vidovic S, Kaplan.M. Optimization of Satureja montana subcritical water extraction process and chemical characterization of volatile fraction of extracts. $\mathrm{J}$ of supercritical Fluids, 2017;120:86-94.

[14] Aliakbariana B, Fathi A, Peregoa P, Dehghani F. Extraction of antioxidants from winery wastes using subcritical water. J. Supercritical Fluids. 2012;65:18-24.

[15] Rodríguez-Meizosoa I, Jaime L, Santoyo S, Senoráns FJ, Cifuentes A, Ibánez E. Subcritical water extraction and characterization of bioactive compounds from Haematococcus pluvialis microalga. J. Pharm. Biomed. Anal. 2010;51:456-463.

[16] Giray ES, Kırıcı S, Kaya DA, Turk M, Sonmez O, Inan M. Comparing the effect of sub-critical water extraction with conventional extraction methods on the chemical composition of Lavandula stoechas. Talanta. 2008;74:930-935. 